\title{
Pilot study of a brief psychological intervention for reducing emotional exhaustion and secondary traumatic stress among physicians of intensive care units in Mexico
}

\author{
Jennifer E. Moreno-Jiménez, ${ }^{1}$ María del Carmen Yeo-Ayala ${ }^{2}$ Andrés Palomera,${ }^{2}$ Luis Manuel Blanco-Donoso, \\ Raquel Rodríguez-Carvajal,' Eva Garrosa, 'Bernardo Moreno-Jiménez
}

Facultad de Psicología, Universidad Autónoma de Madrid, España.

2 Centro Universitario de Ciencias de la Salud, Universidad de Guadalajara, México.

\section{Correspondence:}

Jennifer E. Moreno-liménez

Departamento de Psicología Biológica y de la Salud, Facultad de Psicología, Universidad Autónoma de Madrid.

Calle Ivan Pavlov, 6 ,

Madrid (Cantoblanco),

28049, España

Phone: +34 69246 - 1348

Email: jennifer.moreno@uam.es

Received: 22 June 2020

Accepted: 15 July 2020

Citation:

Moreno-jiménez, J. E., Yeo-Ayala, M. C., Palomera, A., Blanco-Donoso, L. M., Rodríguez-Carvajal, R., Garrosa, E. \& Moreno-jiménez, B. (2020). Pilot study of a brief psychological intervention for reducing emotional exhaustion and secondary traumatic stress among physicians of intensive care units in Mexico. Salud Mental, 43(5), $219-226$

DOI: $10.17711 /$ SM.0185-3325.2020.030

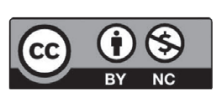

\begin{abstract}
Introduction. Physicians of Intensive Care Units (ICU) have a potential risk to develop negative outcomes such as emotional exhaustion and secondary traumatic stress (STS). Specifically, job demands in these units (i.e., work stressors and emotional effort) may positively predict these outcomes, whereas personal resources such as harmonious passion and self-compassion may diminish them. Objetive. To design a specific intervention for physicians in ICU and provide preliminary evidence of its effectiveness. Method. A brief intervention of five weekly sessions (two hour-sessions) was carried out with four physicians in ICU in a hospital in Mexico. Other four physicians were selected as a control group. The intervention was aimed at reducing emotional exhaustion and STS by increasing harmonious passion and self-compassion, and diminishing the emotional effort. Results. The intervention group showed a significant reduction in: a) work stressors (2/4 physicians; $R C l=.21)$; emotional effort ( $1 / 4$ physicians; $(R C l=.60)$; emotional exhaustion $(2 / 4$ physicians; $R C l=.34)$; and STS (3/4 physicians; $R C l=.26)$. One physician experienced a significant increase in harmonious passion $(R C l=1.00)$, but the intervention seems to maintain high levels of this and self-compassion in comparison with the control group. The control group showed a worse result in its outcomes. Discussion and conclusion. Despite the limitations, this study provides preliminary evidence for effectively reducing emotional exhaustion and STS. Our findings highlight the individual analysis of the effective tools per physician and address interventions focused on harmonious passion and self-compassion. This study calls for future research concerning intervention proposals in ICU with follow-up measures to diminish the negative consequences in the long-term.
\end{abstract}

Keywords: Physicians, intensive care units, intervention, harmonious passion, self-compassion, emotional effort.

\section{RESUMEN}

Introducción. Los médicos de las unidades de Cuidados Intensivos (UCl) presentan un riesgo de desarrollar agotamiento emocional y estrés traumático secundario (ETS). Las demandas laborales en estas unidades (estresores laborales y esfuerzo emocional) pueden predecir positivamente estos resultados, mientras que los recursos personales como la pasión armoniosa y la autocompasión pueden disminuirlos. Objetivo. Diseñar una intervención específica para médicos de $\mathrm{UCl}$ y proporcionar evidencia preliminar de su efectividad. Método. Se realizó una intervención de cinco sesiones semanales (de dos horas de duración cada una) con cuatro médicos de una UCl en un hospital de México. Otros cuatro médicos fueron seleccionados como grupo control. El objetivo fue reducir el agotamiento emocional y el ETS mediante el aumento la pasión armoniosa y la autocompasión; y la disminución del esfuerzo emocional. Resultados. En el grupo de intervención se halló una disminución significativa en: a) estresores laborales ( $2 / 4$ médicos; $R C l=.21$ ); esfuerzo emocional ( $1 / 4$ médicos; $R C l=.60)$; agotamiento emocional $(2 / 4$ médicos; $R C l=.34)$; y ETS $(3 / 4$ médicos; $R C l=.26)$. Un médico experimentó un aumento significativo en la pasión armoniosa $(R C l=1.00)$, en tanto que el resto mantuvo altos niveles de ésta y autocompasión en comparación con el grupo control. Discusión y conclusión. A pesar de las limitaciones, este estudio proporciona evidencia preliminar para reducir el agotamiento emocional y el ETS. Nuestros hallazgos destacan el análisis individual de las herramientas efectivas y destaca las intervenciones centradas en la pasión armoniosa y la autocompasión. Nuestro estudio recalca la importancia de desarrollar investigaciones futuras sobre intervenciones en $\mathrm{UCl}$ con medidas de seguimiento que puedan disminuir las consecuencias negativas a largo plazo.

Palabras clave: Personal médico, unidades de cuidados intensivos, intervención, pasión armoniosa, autocompasión, esfuerzo emocional. 


\section{INTRODUCTION}

Healthcare workers in Intensive Care Units (ICU) are wellknown for presenting several consequences that directly impact on their health and well-being (van Mol et al., 2015), particularly in physicians, who may develop negative outcomes such as burnout (Romani \& Ashkar, 2014) and secondary traumatic stress (STS; Kinker, Arfken, \& Morreale, 2018). Concretely, emotional exhaustion (EE) is the most prevalent among the burnout dimensions (Chuang, Tseng, Lin, Lin, \& Chen, 2016), considered as the feeling of being extremely fatigued due to the prolonged exposure to high workload (Bakker, Demerouti, \& Verbeke, 2004). In contrast, STS is considered an occupational hazard due to the caring task of traumatized patients and its secondary exposure to these traumatic events (Dominguez-Gomez \& Rutledge, 2009). Both EE and STS seem to impact physicians in different ways: a. personally, increasing their stress in personal relationships, depression, and anxiety symptoms, intention to quit (Myhren, Ekeberg, \& Stokland, 2013), and even suicide (Kelly, 2020); and b. professionally, decreasing their productivity, quality of care, and patient satisfaction (Weintraub, Sarosi, Goldberg, \& Waldman, 2020). Despite its relevance, only a few empirical studies have focused on intervention proposal to diminish the negative consequences of working in ICU for healthcare workers (Blanco-Donoso, García Rubio, Moreno Jiménez, de la Pinta, Moraleda Aldea, \& Garrosa, 2017; Gracia-Gozalo et al., 2019), and most were conducted among nurses rather than physicians (Panagioti et al., 2017).

Looking closely, the working conditions that characterize these units make these healthcare workers a highrisk group (van Mol et al., 2015). Chuang et al. (2016) established that the job demands in ICU are those related to workload and time pressure, namely, stressors. These stressors are associated with EE (Bakker \& Demerouti, 2017) and STS (Moreno-Jiménez et al., 2019). Moreover, end-of-life issues linked to ethical decision-making are considered as emotional demands that healthcare workers may deal with and constitute obstacles to overcome (Bakker \& Sanz-Vergel, 2013). In this sense, dealing with these emotional demands involve the use, plan, and control of emotion regulation strategies in work settings (Rodríguez-Carvajal, Moreno-Jiménez, de Rivas Hermosilla, \& Herrero Lázaro, 2011), which has been considered as emotional labor (Martínez-Iñigo, Totterdell, Alcover, \& Holman, 2007). This emotional labor involves a key concept of emotional effort, defined as the "perception of resources invested when meeting emotional requirements of the job" (Quiñones-García, Rodríguez-Carvajal, Clarke, \& Moreno-Jiménez, 2013, p. 364). Thus, meeting the emotional demands in ICU, linked to the need to do a high-quality job, could involve a loss of resources by this emotional effort, leading to EE, as well (Martínez-Iñigo et al., 2007).
Despite these healthcare workers are considered to have a potential risk, current studies highlight their passion for caring and their vocation in their work (Gómez-Salgado, Navarro-Abal, López-López, Romero-Martín, \& Climent-Rodríguez, 2019). This passion for work has been widely studied as an inclination toward work in which the individual has positive feelings and also makes this as part of his/her identity (Pollack, Ho, O'Boyle, \& Kirkman, 2020). The outstanding role of this passion is the distinction between the two types with different associated outcomes (Vallerand, Paquet, Philippe, \& Charest, 2010). Firstly, harmonious passion has been defined as the positive side that involves loving your work keeping harmony between the work and the other life areas. This passion has been strongly associated with more recovery, job satisfaction, positive emotions (see Vallerand, 2008; Vallerand et al., 2003, for a review) and indeed, less EE (Donahue et al., 2012) and STS (Moreno-Jiménez et al., 2019). On the contrary, obsessive passion is characterized by establishing work as a central feature occupying an excessive space and generating unbalance between work and other life areas. This passion has been associated with more rumination, workaholic behaviors, and higher EE (Vallerand et al., 2010) and STS (Moreno-Jiménez et al., 2019). According to the literature reviewed, only one study has focused on passion for work from an intervention proposal and established the use of strengths as a way to increase harmonious passion and, consequently, to increase well-being (Forest et al., 2012). Therefore, we point the need for further research to increase this harmonious passion boosting its positive associated outcomes.

Moreover, current findings in physicians have pointed out the need to mitigate the high prevalence of burnout by increasing personal resources such as self-compassion (Saadat \& Kain, 2018). Self-compassion is defined as a kind and non-judging attitude toward oneself, considering the mistakes as a normal part of human beings (Raab, 2014). Previous findings proposed self-compassion as a way to alleviate energy depletion (i.e., emotional exhaustion) and the cost of caring of patients exposed to traumatic events (i.e., secondary traumatic stress) by this self-care attitudes that diminish the stress response in emotional exhausting context (Beaumont, Durkin, Hollins Martin, \& Carson, 2016). In this regard, self-compassion techniques based on mindfulness practices (see García-Campayo \& Demarzo, 2015 for a review) have proved to be effective in increasing self-compassion in healthcare workers and diminishing the negative outcomes (e.g., burnout; Gracia-Gozalo et al., 2019).

Although the reduction of job demands (e.g., low time pressure and workload, and less emotional communication with patients' relatives) could favor the healthcare workers' well-being (Bakker \& Demerouti, 2013), this may result difficult in an ICU demanding context. Thus, other interventions focused on healthcare workers resources are recommended (Kravits, McAllister-Black, Grant, \& Kirk, 
2010). In this regard, new approaches within the contextual therapies have arisen in work settings providing promising results, such as Acceptance and Commitment Therapies (ACT; Hayes, Strosahl, \& Wilson, 1999). ACT aim to increase acceptance and reduce experiential avoidance related to negative feelings, being associated with positive outcomes such as well-being and better performance (Flaxman \& Bond, 2010). Besides, ACT approaches have shown to be effective in gaining awareness about personal values and commitment toward these values through actions, even in brief interventions with small samples (Gallego-Alberto, Márquez-González, Romero-Moreno, Cabrera, \& Losada, 2019). The use of experiential exercises allows you to work the personal values (e.g., garden metaphor; Hayes et al., 1999) changing the balance between different areas of life, and in turn, establish the closest relationship between work and life to harmonious passion. Therefore, the goals of the present work are twofold: a. to design and describe a brief psychological intervention specifically for physicians working in ICU, and $b$. to provide preliminary evidence about its effectiveness to fill the gap about these interventions in ICU.

\section{METHOD}

\section{Design and procedure}

This study is a quasi-experimental design with an intervention and control group. Concerning the procedure, informative meetings were held, firstly with the person in charge of the ICU, and then with all the physicians of these units, in order to explain the intervention proposal and its benefits. In these meetings, participants were informed and asked of voluntarily participating. Only four physicians agreed to participate, forming the Intervention Group (IG). As they were the only ones who voluntarily agreed to participate, we did not consider gender nor age to include them. On the other hand, another four random physicians of ICU were selected to establish a Control Group (CG) to assess whether the changes were due to the intervention, establishing a similar range of age in the CG in comparison with the IG. The IG and CG were not paired as they are individually analyzed to provide an in-depth picture of the intervention. After that, all participants were assessed in time 1 (previous to start the intervention in the IG), and time 2 (after finishing the intervention in the IG).

\section{Participants}

The sample was composed by eight physicians of ICU in a public hospital in Guadalajara (Mexico). The inclusion criterion was to have a minimum work experience of one year in the ICU, to effectively assess the effect of being exposed enough time to this demanding unit. This minimum work
Table 1

Sociodemographic data of the sample

\begin{tabular}{cccccc}
\hline & Gender & Age & $\begin{array}{c}\text { Years } \\
\text { of WE }\end{array}$ & $\begin{array}{c}\text { In a rela- } \\
\text { tionship }\end{array}$ & $\begin{array}{c}\text { Other } \\
\text { jobs }\end{array}$ \\
\hline $\begin{array}{c}\text { Intervention group } \\
\text { Physician 1 }\end{array}$ & Female & 31 & 6 & Yes & No \\
Physician 2 & Male & 34 & 9 & Yes & Yes $^{1}$ \\
Physician 3 & Male & 23 & 1 & Yes & No \\
Physician 4 & Male & 35 & 10 & Yes & Yes ${ }^{1}$ \\
Control group & & & & & \\
Physician 5 & Female & 23 & 1 & Yes & No \\
Physician 6 & Female & 27 & 4 & No & No \\
Physician 7 & Female & 36 & 13 & Yes & Yes \\
Physician 8 & Female & 40 & 19 & Yes & No \\
\hline
\end{tabular}

Notes: WE $=$ Work Experience; ${ }^{1}$ Weekend shift; ${ }^{2}$ External office.

experience allowed us to include the internal residents that wanted to participate. Participants were selected from the morning shift, having a length of seven hours. All participants signed the written informed consent. Table 1 presents the sociodemographic data of the sample.

\section{Measures and Instruments}

Work stressors (Secondary Traumatic Stress Scale; Meda, Moreno-Jiménez, Palomera, Arias, \& Vargas, 2012). It consists of a 5-item scale that assesses workload (e.g., "The pressure to initially attend to a patient is very high"), social pressure (e.g., "When a patient or relative is a healthcare worker, it results uncomfortable to accomplish my work"), and traumatic tasks (e.g., "I find it difficult to forget situations in which the victim is a minor or elderly person"). The Likert-scale response ranged from 1 "totally disagree" to 4 "totally agree".

Emotional Effort (Emotional Effort scale; QuiñonesGarcía et al., 2013). It consists of a 7-item scale (e.g., "How often do you feel that this activity is the main reason why you feel fatigued at the end of the day?"). The Likert-scale response ranged from 1 "never" to 5 "always".

Passion for Work (Passion for Work Scale; Serrano-Fernández, Boada-Grau, Gil-Ripoll, \& Vigil-Colet, 2017). It consists of a 9-item scale that assesses: a. harmonious passion (e.g., "My work allows me to live all types of experiences"), and b. obsessive passion (e.g., "My mood depends on doing well my job"). The Likert-scale response ranged from 1 "totally disagree" to 7 "totally agree".

Self-compassion (Self-Compassion Scale; García-Campayo \& Demarzo, 2015). This version was shortened in order to avoid the fatigue of the participants, selecting the four items with higher loads in the original validation scale (e.g., "When I fail in something that is important to me, I try to see this issue with perspective"). The Likert-scale response ranged from 1 "rarely" to 5 "almost always". 
Emotional Exhaustion (Nursing Burnout Scale; Moreno-Jiménez, Garrosa-Hernández, González Gutiérrez, 2000). It consists of a 4-item scale to assess the emotional fatigue to carry out the caring tasks (e.g., "I feel physically and mentally exhausted"). The Likert-scale response ranged from 1 "totally disagree" to 4 "totally agree".

Secondary Traumatic Stress (Secondary Traumatic Stress Scale; Meda et al., 2012). It assessed the emotional fatigue (e.g., "I feel emotionally without strength"), cognitive changes (e.g., "This work had made me see the world as unfair"), and stress-related symptomatology (e.g., "Sometimes I think in those patients who died while I was attending them"). It consists of a 14-item scale with a response scale ranging from 1 "totally disagree" to 4 "totally agree".

\section{Data analysis}

Due to the sample size, the Reliable Change Index (RCI) was used per participant linked with the criteria of Jacobson and Truax (1991). Following this, a significant change is found whether the difference between the time 1 and time 2 is greater than the RCI. We included the measure of work stressors as a control variable to assess whether this variable could explain the participants' outcomes.

\section{Intervention proposal}

The intervention was held from April to May 2019 and consisted of five weekly sessions carried out individually in the IG $(n=4)$, each lasting approximately two hours. The main goals of the intervention were: $a$. to reduce EE, and b. to reduce STS. For this purpose, a specific intervention was designed using a psychoeducational intervention (Kravits et al., 2010), the ACT techniques (Hayes et al., 1999), self-compassion techniques (García-Campayo \& Demarzo, 2015), and emotion regulation strategies (Rodríguez-Carvajal et al., 2011) aforementioned. Thus, the specific goals were: a. to increase harmonious passion; $b$. to increase self-compassion, and c. to reduce the emotional effort. The intervention contents and goals are included in Table 2.

\section{Ethical considerations}

This work was accepted by the research ethics committee of the Autonomous University of Madrid (reference number CEI 71- 1276).

Table 2

Content of the specific intervention design to reduce emotional exhaustion and STS among physicians in ICU

\begin{tabular}{|c|c|c|}
\hline Session & Main goal & Content \\
\hline \multirow[t]{2}{*}{1.} & $\begin{array}{l}\text { - Increase physicians' awareness about } \\
\text { the work stressors in ICU. }\end{array}$ & - Identifying daily work stressors in ICU and reflecting about that. \\
\hline & $\begin{array}{l}\text { - Increase their awareness about the } \\
\text { risks of developing STS. }\end{array}$ & $\begin{array}{l}\text { - Psychoeducation of STS and its dimensions (compassion fatigue, shattered assump- } \\
\text { tions and symptomatology). Identifying possible symptoms. }\end{array}$ \\
\hline \multirow[t]{2}{*}{2.} & - Increase harmonious passion for work. & $\begin{array}{l}\text { - Psychoeducation of Passion for work and associated positive outcomes. } \\
\text { - Identifying personal values (e.g. family, partnership, social relationships, work, leisure } \\
\text { time, and educational goals), its importance and satisfaction. } \\
\text { - Assessing the discrepancy between the importance of the personal values and the } \\
\text { time devoted to each of them. }\end{array}$ \\
\hline & $\begin{array}{l}\text { Create a balance in physician's life ac- } \\
\text { tivities through the commitment toward } \\
\text { personal values. }\end{array}$ & $\begin{array}{l}\text { - Working possible barriers to overcome this discrepancy and establishing committed } \\
\text { actions. }\end{array}$ \\
\hline 3. & - Increase self-compassion skills. & $\begin{array}{l}\text { - Self-compassion techniques: thinking about situations in which they committed mis- } \\
\text { takes and listen to their critical voice. } \\
\text { - Reflecting about their critical voice: a) where it comes from; b) what emotion arise, and } \\
\text { c) how it makes them feel. } \\
\text { - Searching alternative explanations and learning a new self-compassionate voice. }\end{array}$ \\
\hline 4. & - Diminish the emotional effort. & $\begin{array}{l}\text { - Identify emotion regulation strategies in different situations: a) emotional suppression } \\
\text { (e.g. avoiding to express any positive/negative emotion) and b) cognitive reappraisal } \\
\text { (e.g. changing the interpretation of a situation to change the perceived emotion). } \\
\text { - Assess whether they are adaptive or generate more emotional effort. } \\
\text { - Acceptance of the distress suffered in difficult ICU-related situations. }\end{array}$ \\
\hline \multirow[t]{2}{*}{5.} & $\begin{array}{l}\text { - Examine whether they have overcome } \\
\text { their drawbacks. }\end{array}$ & - Identify possible future work stressors. \\
\hline & - Establish a preventative plan. & $\begin{array}{l}\text { - Identify personal resources trained and their strengths. } \\
\text { - How to apply them. }\end{array}$ \\
\hline
\end{tabular}




\section{RESULTS}

As shown in Table 3 concerning the IG, two physicians (2 and 3) experienced a significant reduction in their work stressors $(R C I=.21 ; p<.05)$ in the post-treatment (time $2)$. Regarding the emotional effort, only physician 2 experienced a significant reduction $(R C I=.60 ; p<.05)$. In the trained variables, it seems that only physician 3 experienced a significant increase in his harmonious passion $(\mathrm{RCI}=1.00$; $p<.05)$, and none changes were found regarding obsessive passion $(R C I=2.49 ; p<.05)$ and self-compassion $(R C I=1.31$; $p<.05)$. Finally, concerning the outcomes, two physicians (1 and 3 ) significantly reduced $\mathrm{EE}(R C I=.34 ; p<.05)$ and three physicians $(1,2$, and 3$)$ got a significant reduction in $\operatorname{STS}(R C I=.26 ; p<.05)$.

Concerning the control group (Table 4) we found interesting results. Starting with the work stressors, physi-

Table 3

Pre-treatment (time 1) and Post-treatment (time 2) mean scores per variable with the intervention group $(n=4)$

\begin{tabular}{|c|c|c|c|c|}
\hline \multirow[b]{2}{*}{ Variable } & \multicolumn{4}{|c|}{$\begin{array}{c}\text { Intervention group } \\
\text { Physician }\end{array}$} \\
\hline & 1 & 2 & 3 & 4 \\
\hline \multicolumn{5}{|c|}{ Work stressors } \\
\hline Time 1 & 2.4 & 3.4 & 2.2 & 2.8 \\
\hline Time 2 & 2.4 & 3 & 1.4 & 2.8 \\
\hline Change & 0 & $.4^{*}$ & $.8^{*}$ & 0 \\
\hline \multicolumn{5}{|c|}{ Emotional Effort } \\
\hline Time 1 & 1.86 & 3.43 & 2.43 & 4.71 \\
\hline Time 2 & 2 & 2.71 & 1.86 & 4.43 \\
\hline Change & -.14 & $.72^{*}$ & .57 & .28 \\
\hline \multicolumn{5}{|c|}{ Harmonious passion } \\
\hline Time 1 & 6 & 4.5 & 5.25 & 5.75 \\
\hline Time 2 & 5.75 & 5.25 & 6.75 & 5.25 \\
\hline Change & .25 & -.75 & $-1.5^{*}$ & .5 \\
\hline \multicolumn{5}{|c|}{ Obsessive passion } \\
\hline Time 1 & 2.2 & 6.4 & 3.4 & 1 \\
\hline Time 2 & 1 & 5.4 & 3.4 & 1.4 \\
\hline Change & 1.1 & 1 & 0 & -.4 \\
\hline \multicolumn{5}{|c|}{ Self-compassion } \\
\hline Time 1 & 2.5 & 2.5 & 4.25 & 4.75 \\
\hline Time 2 & 3.75 & 3.5 & 5 & 4.75 \\
\hline Change & -1.25 & -1 & -.75 & 0 \\
\hline \multicolumn{5}{|l|}{ EE } \\
\hline Time 1 & 2.5 & 4 & 2.5 & 4 \\
\hline Time 2 & 1.5 & 4 & 1.5 & 4 \\
\hline Change & $1^{*}$ & 0 & $1^{*}$ & 0 \\
\hline \multicolumn{5}{|l|}{ STS } \\
\hline Time 1 & 1.64 & 3.21 & 2.29 & 2.14 \\
\hline Time 2 & 1.21 & 2.79 & 1.36 & 2.07 \\
\hline Change & $.43^{*}$ & $.42^{*}$ & $.93^{*}$ & .07 \\
\hline
\end{tabular}

Notes: $\mathrm{EE}=$ Emotional Exhaustion; STS $=$ Secondary Traumatic Stress. ${ }^{*}$ Reliable Change. cians 5 and 8 experienced a significant increase in time 2 $(R C I=.60 ; p<.05)$, and only one experienced a significant reduction in emotional effort (physician $8 ; R C I=.30$; $p<.05)$. Moreover, we found a significant reduction in harmonious passion in physician $5(R C I=1.22$; $p<.05)$, and obsessive passion was significantly increased in physician 6 $(R C I=.73 ; p<.05)$. Regarding self-compassion skills, we found a significant increase in physician 6 and a decrease in physician $8(R C I=.53 ; p<.05)$. In regard to our outcomes, we found inconclusive results. In the first place, two physicians (6 and 7) experienced a significant reduction in their emotional exhaustion, whereas the other two (5 and 8) experienced a significant increase $(R C I=.21 ; p<.05)$. In the second place, physicians 5,6 , and, 7 presented a significant increase in their STS levels $(R C I=.16 ; p<.05)$.

Table 4

Time 1 and Time 2 mean scores per variable with the control group $(n=4)$

\begin{tabular}{|c|c|c|c|c|}
\hline \multirow[b]{2}{*}{ Variable } & \multicolumn{4}{|c|}{$\begin{array}{c}\text { Control group } \\
\text { Physician }\end{array}$} \\
\hline & 5 & 6 & 7 & 8 \\
\hline \multicolumn{5}{|c|}{ Work stressors } \\
\hline Time 1 & 2.2 & 2 & 2 & 1.8 \\
\hline Time 2 & 3.8 & 2 & 1.8 & 2.4 \\
\hline Change & $-1.6^{*}$ & 0 & .2 & $-.6^{*}$ \\
\hline \multicolumn{5}{|c|}{ Emotional Effort } \\
\hline Time 1 & 3 & 1.57 & 2.29 & 2.71 \\
\hline Time 2 & 3 & 1.29 & 2 & 1.86 \\
\hline Change & 0 & .28 & .29 & $.85^{*}$ \\
\hline \multicolumn{5}{|c|}{ Harmonious passion } \\
\hline Time 1 & 6.5 & 6.75 & 5 & 6.5 \\
\hline Time 2 & 4.75 & 7 & 5.75 & 6.75 \\
\hline Change & $1.75^{\star}$ & -.25 & -.75 & -.25 \\
\hline \multicolumn{5}{|c|}{ Obsessive passion } \\
\hline Time 1 & 2.6 & 1.4 & 3 & 2.2 \\
\hline Time 2 & 3.2 & 2.7 & 3 & 2.8 \\
\hline Change & -.6 & $-1.3^{*}$ & 0 & -.6 \\
\hline \multicolumn{5}{|c|}{ Self-compassion } \\
\hline Time 1 & 3.5 & 3 & 3.5 & 4 \\
\hline Time 2 & 3.25 & 3.75 & 4 & 3 \\
\hline Change & -.25 & $-.75^{\star}$ & -.5 & $1^{*}$ \\
\hline \multicolumn{5}{|l|}{ EE } \\
\hline Time 1 & 2.25 & 1.75 & 2 & 1 \\
\hline Time 2 & 3.25 & 1.5 & 1.5 & 2 \\
\hline Change & $-1^{*}$ & $.25^{\star}$ & $.5^{*}$ & $-1^{*}$ \\
\hline \multicolumn{5}{|l|}{ STS } \\
\hline Time 1 & 2.29 & 1.5 & 1.86 & 1.41 \\
\hline Time 2 & 2.57 & 2.86 & 1.86 & 1.57 \\
\hline Change & $.28^{*}$ & $1.36^{*}$ & 0 & $.16^{*}$ \\
\hline
\end{tabular}

Notes: EE = Emotional Exhaustion; STS $=$ Secondary Traumatic Stress. *Reliable Change. 


\section{DISCUSSION AND CONCLUSION}

Our findings contribute to the existing literature providing preliminary evidence of an effective psychological intervention with physicians in ICU that has proved to reduce the negative outcomes in the short-term in this specific sample. Moreover, we also contribute with a novel design of a brief intervention adapted to this work setting. However, this work also encounters limitations concerning the sample size and the length of the intervention, which undoubtedly may impact on its applicability and the generalization of the results. Despite this, this pilot study provides an individual analysis of each physician that could provide valuable insights into the existing gap in this topic. Therefore, our study calls for future intervention proposals focusing on these healthcare workers.

Firstly, we focused on the intervention group to check its effectiveness. After five intervention sessions, we found that $2 / 4$ physicians presented a significant clinical reduction in EE whereas 3/4 presented this reduction in STS. These are promising results taking into account that the control group experienced a significant increase in EE (2/4 physicians) and STS (3/4 physicians). Thus, the intervention seems to be a valuable and useful tool to clinically diminish these negative outcomes, which are associated with mental health problems, such as depression, anxiety, and physicians' intention to quit (Myhren et al., 2013; Romani \& Ashkar, 2014). Besides, examining individual changes allowed us to determine the possible mechanism of change for an in-depth analysis of the intervention. Taking a closer look at our findings, physician 1 did not show any clinically significant change neither in the job demands in ICU (i.e., work stressors and emotional effort) nor personal resources (i.e., harmonious passion and self-compassion), finding in the latter a high baseline. In this sense, the intervention could contribute to maintaining these high levels and getting this reduction in EE and STS by the psychoeducational work (Kravits et al., 2010). This psychoeducational work may increase the awareness of the negative outcomes and enhance coping skills to face the work stressors, as they seem to not be increased in time 2. This fact highlights that when the physicians' resources are high enough, only a psychoeducational work could be effective to diminish the negative outcomes, as they may accomplish their duties by using their personal resources by diminishing the demands (Bakker et al., 2004; Bakker \& Sanz-Vergel, 2013). In contrast, physician 2 significantly reduced the demands (i.e., work stressors and emotional effort) and this may reduce their STS levels in time 2. These findings highlight the direct relationship between job demands in ICU and STS (Meda et al., 2012; Moreno-Jiménez et al., 2019). Moreover, physician 3 experienced a significant clinical reduction in work stressors and a significant increase in harmonious passion, with the associated reduction in both negative outcomes (i.e., EE and STS). These facts could suggest that the ACT intervention could be useful increasing the harmonious passion, and possibly affecting the perception of the work stressors, as Lavigne, Forest, Fernet, and Crevier-Braud (2014) suggest. Following these authors, the harmonious passionate workers may perceive the work stressors as more controllable and challenging rather than a hindrance, which may be associated with less EE. Our findings provide empirical support for this statement.

Moreover, it is relevant to highlight that this is the physician with the less work experience (one year), so our findings suggest that including this kind of intervention which boosts positive personal resources could be effective in the early stages of the physicians' career. On the contrary, physician 4 seems not to be affected by the intervention, finding no significant changes in none dimension. Interestingly, this is the physician with higher levels of obsessive passion, which could be associated with the fact that he has another job apart from working in this unit. Besides, it seems plausible that the internalization made by this type of workers (Pollack et al., 2020), in which they are more dependent on external contingencies, need a greater length of the intervention working in the harmonious passion, and in turn, to provoke significant changes. Thus, the work-related attitudes internalized as this obsessive passion could diminish the positive impact of the intervention, as previous findings supported in which the harmonious passion is related to the use of strengths and positive outcomes (Dubreuil, Forest, \& Courcy, 2014).

Secondly, examining the control group, we found interesting results. Our findings showed a worse state in time 2 concerning the work stressors in two physicians and STS in three physicians. We found as well a significant decrease in harmonious passion in physician five and a significant increase in obsessive passion in physician six. In that regard, it seems that the control group had lost their personal resources by the time work stressors arised, as is supported by Bakker and Demerouti (2017), and this may be associated with a significant increase in EE and STS. Additionally, these findings directly suggest that our intervention succeeded in maintaining high levels of positive personal resources (i.e., harmonious passion and self-compassion) in high demanding contexts (Blanco-Donoso et al., 2017). Furthermore, the results obtained in EE in the control group confirmed these hypotheses. On the one hand, two physicians experienced a significant increase in EE (physicians 5 and 8), being those with a significant increase in their work stressors. On the other hand, the other two physicians (6 and 7) experienced a significant decrease, with lower levels of work stressors. This fact suggests the close relationship between work stressors and the energy depletion of EE in line with the argument of Bakker and Demerouti (2017). However, the findings obtained in self-compassion provide controversial conclusions, being significantly increased in 
physician 6 , at the same time that she has no change in the work stressors, and significantly reduced in physician 8, finding a significant increase in work stressors. It seems that the low levels of work stressors could facilitate the development of self-compassion skills, whereas this could be difficult in contexts with high work stressors (Blanco-Donoso et al., 2017). In addition, these findings also underline that our session based on self-compassion techniques needs improvements, as we did not obtain any change in this resource in the intervention group. One possible explanation might be the experiential exercise used linked to the format, finding current studies mindfulness practices as a valuable means to improve this self-compassion through brief daily audio-guided practices (5-8 $\mathrm{min}$ ) (Gracia-Gozalo et al., 2019; Rodríguez-Carvajal, García-Rubio, Paniagua, García-Díex, \& de Rivas, 2016).

Finally, the limitations of this study potentially point to be cautious regarding our results. The high workload and pressure in ICU and the lack of personnel make it difficult to establish a group intervention for a period of time, as they need to stay in the unit. In addition, the length of their shifts and their exhaustion levels after that impeded to establish these interventions as an extra working time. For these reasons, we organized specifically brief individual interventions to allow them to participate for a brief period of time but getting a small sample size and a small number of sessions. Moreover, the absence of a randomized selection of the four volunteer physicians could involve that they were more engaged with the intervention as they decided to participate. This could facilitate the insights and enhance the resources trained boosting the positive changes. However, this format strengthens the possibility to adapt to an ICU context and deepen into the physicians' needs, supposing a step forward of those interventions held via-online (Gracia-Gozalo et al., 2019). Additionally, the inclusion of physicians with less work experience also pointed out the need of preventing these negative outcomes from the early stages in their careers, as they are seemingly exposed to the job demands in ICU and they might need to boost their personal resources to overcome these demands. Furthermore, the inclusion of working harmonious passion through ACT techniques allowed us to control other possible explanations for the improvements in the intervention group (i.e., leisure activities and recovery time after work). In this sense, except for physician 1 that already had a small discrepancy between their personal values and the time devoted to each of them, the rest presented a big discrepancy, favoring the work in values and committed actions toward these by analyzing possible barriers.

The present work establishes the relevance of developing specific interventions for physicians in demanding ICU contexts and provides them with the resources needed to overcome their drawbacks. As the ICU context encountered several obstacles to properly apply the intervention (e.g., limited time and spaces), this work underlines some limitations that future research should take into consideration. Firstly, our findings reveal that diminishing job demands could reduce the negative outcomes, especially emotional exhaustion, thus, the organization should take not only individual but also organizational measures to protect these workers (Blanco-Donoso et al., 2017; Panagioti et al., 2017). Secondly, when these job demands are reduced, the role of the health psychologists seems crucial in ICU to intervene boosting the personal resources, such as harmonious passion through ACT techniques that provide valuable findings in this brief intervention and reveal to buffer the impact of the job demands in healthcare workers' well-being. Thirdly, in those physicians with higher levels of positive personal resources, giving psychoeducational intervention could prevent them from the future development of negative consequences such as STS. All in all, this work is the first step to continue improving the body of literature concerning psychological well-being in healthcare workers of ICU.

\section{Funding}

This research was supported by the pre-doctoral fellowship "FPIUAM 2017" linked to a Brief Stay Fellowship FPI-UAM 2018 of "Universidad Autónoma de Madrid", and the I+D+I National Project of "Ministerio de Ciencia e Innovación" (PID2019106368GB-I00) AEI/10.13039/501100011033.

\section{Conflicts of interest}

The authors declare they have no conflicts of interests.

\section{REFERENCES}

Bakker, A. B., \& Demerouti, E. (2013). La teoría de las demandas y los recursos laborales. Revista de Psicología del Trabajo y de las Organizaciones, 29(3), 107-115. doi: 10.5093/tr2013a16

Bakker, A. B., \& Demerouti, E. (2017). Job demands-resources theory: Taking stock and looking forward. Journal of Occupational Health Psychology, 22(3), $273-$ 285. doi: $10.1037 /$ ocp0000056

Bakker, A. B., \& Sanz-Vergel, A. I. (2013). Weekly work engagement and flourishing: The role of hindrance and challenge job demands. Journal of Vocational Behavior, 83(3), 397-409. doi: 10.1016/j.jvb.2013.06.008

Bakker, A. B., Demerouti, E., \& Verbeke, W. (2004). Using the job demands-resources model to predict burnout and performance. Human Resource Management, 43(1), 83-104. doi: 10.1002/hrm.20004

Beaumont, E., Durkin, M., Hollins Martin, C. J. H., \& Carson, J. (2016). Compassion for others, self-compassion, quality of life and mental well-being measures and their association with compassion fatigue and burnout in student midwives: A quantitative survey. Midwifery, 34, 239-244. doi: 10.1016/j.midw.2015.11.002

Blanco-Donoso, L. M., García Rubio, C., Moreno Jiménez, B., de la Pinta, M. L. R., Moraleda Aldea, S., \& Garrosa, E. (2017). Intervención breve basada en ACT y mindfulness: Estudio piloto con profesionales de enfermería en UCI y Urgencias. International Journal of Psychology and Psychological Therapy, 17(1), 57-63.

Chuang, C., Tseng, P., Lin, C., Lin, K., \& Chen, Y. (2016). Burnout in the intensive care unit professionals. A systematic review. Medicine, 95(50), e5629. doi: 10.1097/MD.0000000000005629

Dominguez-Gomez, E., \& Rutledge, D. N. (2009). Prevalence of Secondary Traumatic Stress Among Emergency Nurses. Journal of Emergency Nursing, 35(3), 199-204. doi: 10.1016/j.jen.2008.05.003 
Donahue, E. G., Forest, J., Vallerand, R. J., Lemyre, P. N., Crevier-Braud, L., \& Bergeron, É. (2012). Passion for work and emotional exhaustion: The mediating role of rumination and recovery. Applied Psychology: Health and Well-Being, 4(3), 341-368. doi: 10.1111/j.1758-0854.2012.01078.x

Dubreuil, P., Forest, J., \& Courcy, F. (2014). From strengths use to work performance: The role of harmonious passion, subjective vitality, and concentration. Journal of Positive Psychology, 9(4), 335-349. doi: 10.1080/17439760.2014.898318

Flaxman, P. E., \& Bond, F. W. (2010). A randomised worksite comparison of acceptance and commitment therapy and stress inoculation training. Behaviour Research and Therapy, 48(8), 816-820. doi: 10.1016/j.brat.2010.05.004

Forest, J., Mageau, G. A., Crevier-Braud, L., Bergeron, É., Dubreuil, P., \& Lavigne, G. L. (2012). Harmonious passion as an explanation of the relation between signature strengths' use and well-being at work: Test of an intervention program. Human Relations, 65(9), 1233-1252. doi: 10.1177/0018726711433134

Gallego-Alberto, L., Márquez-González, M., Romero-Moreno, R., Cabrera, I., \& Losada, A. (2019). Pilot study of a psychotherapeutic intervention for reducing guilt feelings in highly distressed dementia family caregivers (Innovative practice). Dementia. doi: 10.1177/1471301219886761

García-Campayo, J., \& Demarzo, M. (2015). Mindfulness y compasión: la nueva revolución. Barcelona: Siglantana.

Gracia Gozalo, R., Ferrer Tarrés, J., Ayora Ayora, A., Alonso Herrero, M., Amutio Kareaga, A., \& Ferrer Roca, R. (2019). Application of a mindfulness program among healthcare professionals in an intensive care unit: Effect on burnout, empathy and self-compassion. Medicina Intensiva (English Edition), 43(4), 207-216. doi: 10.1016/j.medine.2019.03.006

Gómez-Salgado, J., Navarro-Abal, Y., López-López, M. J., Romero-Martín, M., \& Climent-Rodríguez, J. A. (2019). Engagement, passion and meaning of work as modulating variables in nursing: A theoretical analysis. International Journal of Environmental Research and Public Health, 16(1), 108. doi: 10.3390/ ijerph16010108

Hayes, S. C., Strosahl, K. D., \& Wilson, K. G. (1999). Acceptance and Commitment Therapy: An experiential approach to behavior change. New York: Guilford Press.

Jacobson, N. S., \& Truax, P. (1991). Clinical significance: a statistical approach to defining meaningful change in psychotherapy research. Journal of consulting and clinical psychology, 59(1), 12-19. https://doi.org/10.1037//0022006x.59.1.12

Kelly, L. (2020). Burnout, Compassion fatigue, and secondary trauma in nurses: Recognizing the occupational phenomenon and personal consequences of caregiving. Critical Care Nursing Quarterly, 43(1), 73-80. doi: 10.1097/ CNQ.0000000000000293

Kinker, B., Arfken, C., \& Morreale, M. (2018). Secondary traumatic stress in medical students. Academic Psychiatry, 42(1), 181-182. doi: 10.1007/s40596-017-07674

Kravits, K., McAllister-Black, R., Grant, M., \& Kirk, C. (2010). Self-care strategies for nurses: A psycho-educational intervention for stress reduction and the prevention of burnout. Applied Nursing Research, 23(3), 130-138. doi: 10.1016/j.apnr.2008.08.002

Lavigne, G. L., Forest, J., Fernet, C., \& Crevier-Braud, L. (2014). Passion at work and workers' evaluations of job demands and resources: a longitudinal study. Journal of Applied Social Psychology, 44(4), 255-265. doi: 10.1111/jasp.12209

Martínez-Iñigo, D., Totterdell, P., Alcover, C. M., \& Holman, D. (2007). Emotional labour and emotional exhaustion: Interpersonal and intrapersonal mechanisms. Work \& Stress, 21(1), 30-47. doi: 10.1080/02678370701234274

Meda, R., Moreno-Jiménez, B., Palomera, A., Arias, E., \& Vargas, R. (2012). La Evaluación del Estrés Traumático Secundario. Estudio Comparado en Bomberos y Paramédicos de los Servicios de Emergencia de Guadalajara, México. Terapia Psicológica, 30(2), 31-41. doi: 10.4067/S0718-48082012000200003

Moreno-Jiménez, B., Garrosa Hernández, E. \& González Gutiérrez, J. L. (2000). El Desgaste profesional de enfermería. Desarrollo y validación factorial del CDPE. Archivos de Prevención de Riesgos Laborales, 3(1), 18-28.
Moreno-Jiménez, J. E., Rodríguez-Carvajal, R., Chico-Fernández, M., Lecuona, Ó., Martínez, M., Moreno-Jiménez, B., ... Garrosa, E. (2019). Risk and protective factors of secondary traumatic stress in Intensive Care Units: An exploratory study in a hospital in Madrid (Spain). Medicina Intensiva (English Edition), (xx), 1-8. doi: 10.1016/j.medine.2019.06.013

Myhren, H., Ekeberg, Ø., \& Stokland, O. (2013). Job satisfaction and burnout among intensive care unit nurses and physicians. Critical Care Research and Practice, 1-6. doi: 10.1155/2013/786176

Panagioti, M., Panagopoulou, E., Bower, P., Lewith, G., Kontopantelis, E., ChewGraham, C., ... Esmail, A. (2017). Controlled interventions to reduce burnout in physicians: A systematic review and meta-analysis. JAMA Internal Medicine, 177(2), 195-205. doi: 10.1001/jamainternmed.2016.7674

Pollack, J. M., Ho, V. T., O’Boyle, E. H., \& Kirkman, B. L. (2020). Passion at work: A meta-analysis of individual work outcomes. Journal of Organizational Behavior, 41(4), 311-331. doi: 10.1002/job.2434

Quiñones-García, C., Rodríguez-Carvajal, R., Clarke, N., \& Moreno-Jiménez, B. (2013). Development and cross-national validation of the Emotional Effort Scale (EEF). Psicothema, 25(3), 363-369. doi: 10.7334/psicothema2012.289

Raab, K. (2014). Mindfulness, self-compassion, and empathy among health care professionals: A review of the literature. Journal of Health Care Chaplaincy, 20(3), 95-108. doi: 10.1080/08854726.2014.913876

Rodríguez-Carvajal, R., García-Rubio, C., Paniagua, D., García-Diex, G., \& de Rivas, S. (2016). Mindfulness Integrative Model (MIM): Cultivating positive states of mind towards oneself and the others through mindfulness and self-compassion. Anales de Psicología, 32(3), 749-760. doi: 10.6018/analesps.32.3.261681

Rodríguez-Carvajal, R., Moreno-Jiménez, B., de Rivas Hermosilla, S., \& Herrero Lázaro, M. (2011). Recursos personales positivos en la relación con el paciente: las Estrategias de regulación emocional. Norte de Salud Mental, 38-48. Retrieved from https://pdfs.semanticscholar.org/81ba/54e810f0ad2af0e0a8244 cb1d7db21b3232b.pdf

Romani, M., \& Ashkar, K. (2014). Burnout among physicians. Libyan Journal of Medicine, 9(1), 23556. doi: 10.3402/ljm.v9.23556

Saadat, H., \& Kain, Z. N. (2018). Wellness interventions for anesthesiologists. Current Opinion in Anaesthesiology, 31(3), 375-381. doi: 10.1097/ ACO.0000000000000598

Serrano-Fernández, M. J., Boada-Grau, J., Gil-Ripoll, C., \& Vigil-Colet, A. (2017). Spanish adaptation of the Passion Toward Work Scale (PTWS). Anales de Psicología, 33(2), 403-410. doi: 10.6018/analesps.33.2.240521

Vallerand, R. J. (2008). On the psychology of passion: In search of what makes people's lives most worth living. Canadian Psychology/Psychologie Canadienne, 49(1), 1-13. doi: 10.1037/0708-5591.49.1.1

Vallerand, R. J., Blanchard, C., Mageau, G. A., Koestner, R., Ratelle, C., Léonard, M., ... Marsolais, J. (2003). Les passions de l'âme: On obsessive and harmonious passion. Journal of Personality and Social Psychology, 85(4), 756-767. doi: 10.1037/0022-3514.85.4.756

Vallerand, R. J., Paquet, Y., Philippe, F. L., \& Charest, J. (2010). On the role of passion for work in burnout: A process model. Journal of Personality, 78(1), 289-312. doi: 10.1111/j.1467-6494.2009.00616.x

van Mol, M. M. C., Kompanje, E. J. O., Benoit, D. D., Bakker, J., \& Nijkamp, M. D. (2015). The prevalence of compassion fatigue and burnout among healthcare professionals in intensive care units: A systematic review. PLOS ONE, 10(8), e0136955. doi: 10.1371/journal.pone.0136955

Weintraub, A. S., Sarosi, A., Goldberg, E., \& Waldman, E. D. (2020). A cross-sectional analysis of compassion fatigue, burnout, and compassion satisfaction in pediatric hematology-oncology physicians in the United States. Journal of Pediatric Hematology/Oncology, 42(1), e50-e55. doi: 10.1097/MPH.0000000000001548 